\title{
KEYNESIAN ISSUES \\ AND \\ ECONOMIC THEORY
}

Jean-Michel GRANDMONT

March 1989

N० 8907 


\section{KEYNESIAN ISSUES AND ECONOMIC THEORY}

\section{A B STRACT}

Recent research helped in clarifying the nature of short run price and quantity adjustments in Keynesian macroeconomic models, and the possible causes of a persistent labour excess supply. It is argued, however, that theories involving imperfect competition and real wage "rigidities" generate "Classical" unemployment, where multipliers act through supply side effects, while nominal inertia seems to be at the root of truly "Keynesian" multipliers. The appraisal contains also a nontechnical presentation of recent models of endogenous expectations-driven business fluctuations (cycles, "sunspots"). Monetary policy can have then persistent real effects under complete information ("money as sunspot").

Keywords : Classical unemployment, Keynesian unemployment, business cycles.

JEL Classification : $021,023,131$.

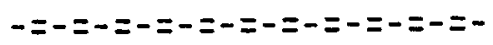 \\ PROBLEMES KEYNESIENS ET THEORIE ECONOMIQUE}

\section{RESUME}

Les efforts de recherche récents ont permis de clarifier la nature des ajustements de court terme de prix et de quantités dans les modèles macroéconomiques keynésiens, et les causes possibles d'un chômage persistant. $L^{\prime}$ analyse montre cependant que les modèles de concurrence imparfaite comportant des "rigidités" du salaire réel engendrent du chômage "Classique", où les multiplicateurs agissent par des effets d'offre, tandis qu'une inertie nominale semble être à la base des multiplicateurs "keynésiens". Cette revue contient également une présentation non technique des modèles récents de fluctuations économiques endogènes (cycles, "taches solaires"). La politique monétaire peut alors avoir des effets réels persistants en information complète ("la monnaie comme tache solaire").

Mots clés : Chômage classique, Chômage keynesien, fluctuations économiques.

Classification JEL : $021,023,131$. 


\section{KEYNESIAN ISSUES AND ECONOMIC THEORY ${ }^{*}$}

Jean-Miche1 Grandmont ${ }^{\star *}$

I wish first to say that I am very happy to participate in this Anniversary Symposium. The Scandinavian Journal of Economics has always been under its various names, an interesting and helpful friend of ours during its 90 years of existence. I am glad to be here to wish the Journal longue vie and continuing success.

I must confess nevertheless that I feel a little out of place, being a so-called microeconomist, to participate in a conference gathering mostly macroeconomists. Although Axe 1 Leijonhufvud remarked humorously some time ago that the totems idolized by the two tribes presented disturbing similarities, I cannot help but finding the recent ritual behaviour of part of the macroeconomics community somewhat confusing. There are indeed heated debates among microeconomists about the relevance of particular theories, but one rarely hears one camp accusing another of "failure on a grand scale" (Lucas and Sargent (1979)). More substantively, it is surprising to see nowadays some "New Classical" (NC) macroeconumists claim that the distinctive and novel feature of their research strategy - the so-called "equilibrium approach" - is to portray economic units as entities optimizing an objective function under well defined constraints describing the market or social institutions through which they interact. I would have thought that understanding the aggregate behaviour of economic or social systems from sound choice-theoretic principles has been, well before 1972 or 1936, one of the goals shared by many microeconomic and 
macroeconomic theorists of different persuasions, including Friedman, Hicks, Kalecki, Keynes, Modigliani, Patinkin, Samuelson, Solow or Tobin.

Proponents of the exclusive use of the "equilibrium approach" to macroeconomic analysis seem moreover to overestimate somewhat the ability of current microeconomic models to produce reliable quantitative macroeconomic predictions. It is known, in particular from the works of Sonnenschein, Debreu and others, that optimization does not place any restriction on aggregate behaviour when the distribution of individual characteristics (tastes, endowments, technologies) is arbitrary. NC theorists often employ small scale dynamic microeconomic specifications with only a few commodities, identical households and firms. Such small scale laboratory models yield indeed useful qualitative insights. Yet they have only the status of examples or parables, and one cannot be sure that their "aggregate" quantitative predictions would survive a realistic formulation with many commodities or heterogenous households and firms. Until the difficult problems of aggregation in dynamic economic models are resolved, it appears legitimate to use the oldfashioned pragmatic approach to quantitative macroeconomics, by mixing the qualitative insights of microeconomic theory with the econometric study, without much theoretical prejudices, of economic aggregates. I understand that, beyond the rhetorics about the "equilibrium approach", this is what many macroeconomists are still actually doing in their applied work.

The origin of quite a few recurrent controversies in macroeconomics, including some of the present ones, may be traced back to a long standing conflict between two contrasted views about the workings of a capitalist economy. The "conservative" view, which is often associated with so-called 
"Classical" economists of different vintages, stresses the virtues of the market system, and its inherent stability. These economists have sometimes to admit, as for instance during the Great Depression or in Europe nowadays, that adjustments are costly and may take some time. But they tend to trust the selfcorrecting mechanisms of free markets and to confine the role of Governments to the enforcement of competition and to the implementation of simple policy rules such as a predetermined constant moderate rate of growth of the money supply. In recent times, some (but not all) NC macroeconomists went even as far as claiming that the systematic (i.e. deterministic) part of Government policies should have no real consequences if properly understood and anticipated by the private sector. The opposing "activist" view, which is associated with "Keynesian" economists, stresses in contrast the instability of the capitalist system, and the permanent losses resulting from periodic depressions and the unemployment of resources. These economists advocate accordingly countercyclical policies to stabilize short term fluctuations and to implement full employment through active demand management. Keynesian economists believe that once this objective is achieved, competitive markets do allocate resources efficiently and recommend accordingly systematic supply side policy measures, agreeing in this regard with Classical economists, to foster long term capacity growth.

Political differences play surely an important role in a field where giving policy advices to Governments is, for good and bad, so strong an activity. Yet it may be more useful, as far as scientific theoretical developments are concerned, to view the evolution of macroeconomic analys is and of parallel advances in microeconomic or game theory, as a continuing struggle 
to get a better understanding of dynamic socioeconomic equilibrium and disequilibrium processes. J.M. Keynes' General Theory, as well as J. Hicks' Value and Capital, were attempts to escape from the static long run competitive equilibrium of the classics, in order to evaluate the influence of wage stickiness and changing expectations on consumption, saving, investment, portfolio choices and the sequence of short run (dis)equilibrium situations of a capitalist economy. The works of Lucas on business cycles $(1972,1975)$ can be interpreted as attempts to understand, in fully specified microeconomic models with endagenous prices and wages, an important piece of the Keynesian paradigm: why there are nominal "rigidities" in the economic system or more specifically, why nominal shocks to aggregate demand may have real "multiplier" effects. It is now more and more recognized that the specific answers given by the NC school to that question, which rested upon the presence of a strong intertemporal substitution between consumption and leisure engineered through real interest rate movements, were empirically inadequate - a fact that should perhaps have been more widely apparent at the outset. Research along this line produced nevertheless valuable new conceptual tools to analyze the dynamics of a market economy in contexts involving risky prospects and incomplete information. There is now a large inventory of research works trying to understand from sound choice-theoretic principles the persistence of significant disequilibria in labour markets (implicit contracts, efficiency wages, insider outsider theories). It is fair to say that the profession is still looking for a convincing microeconomic explanation of the nominal wage or price "rigidities" that seem to occupy so central a place in the Keynesian story. Whatever synthesis may lie ahead, the methodological advances made during the 
NC episode, as we 11 as the quieter but not less important contributions made during that period by general equilibrium or game theorists in the theory of dynamic markets or games under incomplete and asymmetric information, will remain with us long after the macroeconomic controversies of the 1970's will have faded away.

1 chose to concentrate in what follows on three issues. The first one concerns the microeconomic foundations of the quantitative adjustments that take place in short run Keynesian macroeconomic models. In addition to showing that such models can be firmly rooted in modern general equilibrium analysis, consideration of this issue yields an important distinction between two types of unemployment regimes, that are characterized by markedly different responses of the system to short run policy shocks. In situations of "Classical" unemployment, aggregate demand shocks have no impact on the activity level, or generate multipliers that operate through supply side effects. In contrast, demand shocks lead to multipliers that do not rely on such supply side effects when the unemployment regime is "Keynesian" (Section 1). The second issue concerns the relevance of imperfect competition models to understand the unemployment phenomenon. We shall see that models involving imperfect competition on the goods markets and real wage "rigidities" (e.g. implicit contracts, efficiency wages, insiders-outsiders models) lead in fact to situations of "Classical" unemployment. To generate "Keynesian" unemployment, one needs at least to supplement such models with nominal "rigidities" of some sort (Section 2). Finally, I shall review in Section 3 recent microeconomic theories that seems to lend credit to an old Keynesian theme, namely that a significant part of economic fluctuations may be attributed to volatile 
expectations. A by-product of this sort of analys is is that nominal shocks to aggregate demand (e.g. the money supply) may have persistent real effects even in a competitive framework with complete information and self-fulfilling expectations.

\section{Classical and Keynesian unemployment}

An important piece of the Keynesian paradigm about the short run determination of economic activity is that unemployment is due to a deficient demand. Firms would like to sell more but they are prevented from doing so because demand is low. Employment, hence the households' income, is then also low, which contributes further to depress demand. In its simplest formulation, this process leads to an output leve $1 Y$ that is determined in a given period by the well known textbook equation

$$
Y=C(R(Y), p, W)+G \text {, }
$$

where consumption $C$ depends upon current real disposable income $R(Y), G$ stands for the Government's real expenditures, while $p, w$ are the current money price of output and the current money wage, respectively. The policy recommendations follow from the diagnosis : to raise employment in the short run, one should increase aggregate demand.

In this story, exchanges take place at given prices and wages, and the burden of short run adjustments falls exclusively upon output. The traditional macroeconomic formulations used in the sixties did not offer, however, a clear choice-theoretic explanation of the quantitative adjustments that were supposed to occur. Following the leads of Hansen (1951), Patinkin (1956) and the reappraisal of Keynes made by Clower (1965) and Leijonhufvud (1968), the issue was 
clarified in the seventies by Barro and Grossman (1971, 1974, 1976), Benassy (1973, 1977), Malinvaud (1977), through a series of examples that unveiled the role of quantitative signals, as perceived by the traders in addition to the price system, to achieve a short run equilibrium in such a framework. The general microeconomic structure of this class of models is now well known, and I need only to sketch here the arguments in a simple example à la Barro and Grossman, involving three commodities (output, labour, money), a representative firm producing output from labour according to the production function $Y=F(E)$, a representative household, and the Government ${ }^{1}$.

The basic point is that the money price of output $p$ and the money wage $w$ are predetermined at the outset of the period under consideration, e.g. through imperfect competition, while an equilibrium is obtained within the period through quantity rationing. In a Keynesian unemployment regime, supply is rationed on both markets for output and for labour. Specifically, the firm perceives a constraint on its sales of the form $Y \leq \bar{Y}$. The constraint is binding, i.e. it prevents the firm to achieve its profit maximizing output $Y(w / p)$; the demand for labour is then $F^{-1}(\bar{Y})$. Similarly, the household perceives a binding constraint on labour supply of the form $L \leq \bar{L}$, where $\bar{L}$ is less than the (inelastic) available labour force $L^{\star}$. Equilibrium of the labour market requires that the ration $\bar{L}$ be equal to labour demand $F^{-1}(\bar{Y})$. Giver such a quantitative constraint on labour supply, the household's effective demand is $C(R(\bar{Y}), p, W)$. Equilibrium of the good market is then obtained by setting the ration $\bar{Y}$ equal to aggregate demand

$$
\bar{Y}=C(R(\bar{Y}), p, W)+G
$$

which is equivalent to (1.1) since the equilibrium output level is equal to $\bar{Y}$. 
By Walras' law, the remaining market for money is also in equilibrium.

An outcome of this formulation is that not all predetermined configurations $(p, w)$ lead to a Keynesian unemployment equilibrium. The solution of (1.2) must indeed satisfy the constraints

$$
\bar{Y}<Y(w / p), \quad \bar{Y}<Y^{*}=F\left(L^{*}\right),
$$

which express the fact that there is an excess supply on both markets for output and for labour. In the plane $(p, w)$, this corresponds to the region to the right of the curves $L_{2}$ and $L_{3}$ in Fig. 1 , the equations of which are obtained by setting $\bar{Y}$ equal to $Y(w / p)$ and to $Y^{*}$ in $(1.2)$, respectively. In addition, there may be situations where unemployment is not due to a deficient aggregate demand but rather to the low profitability of productive activities. Such a situation occurs when the predetermined pair $(p, w)$ is such that $Y(W / p)<Y^{*}$, i.e. the real wage $w / p$ exceeds the marginal productivity of labour at full employment $F^{\prime}\left(L^{\star}\right)$, and when the solution of $(1.2)$ is greater than $Y(w / p)$. There is then unemployment with an excess demand for the good : output, and thus employment, is no longer demand-determined as in the Keynesian case but is limited by the supply side of the market, i.e. by the profit maximizing output $Y(w / p)$. This regime, called "Classical unemployment" by Malinvaud (1977), corresponds to pairs $(p, w)$ that lie above the line $L_{1}$ and to the left of the curve $L_{2}$ in Fig. $1^{2}$. The two types of unemployment are likely to prevail simultaneously in actual economies, since some productive sectors may experience a low demand, while others face high real costs of production. In the simple case described in Fig. 1, both kinds of unemployment coexist in the Keynesian region when $w / p>F^{\prime}\left(L^{*}\right)$. 


\section{Fig. 1}

Models of this sort are incomplete since they do not specify how prices are determined. Yet they yield valuable insights that carry over to more realistic frameworks with endogenous price setting. The first one concerns the importance of the use of money in the exchange process in order to explain the occurrence of Keynesian unemployment. Firms and households leave apparently some trading opportunities unexploited in such a regime (Barro (1981)) : in the simple example described above, both parties could be better off by exchanging directly labour for output at the quoted price and wage, and one may wonder why they do not do so. The answer is that such improving trades are generally unfeasible in a decentralized economy involving different goods and services that are exchanged in different locations : owing to the prohibitive costs associated with bartering, and to the lack of "double coincidence of wants" when traders meet in a particular market, money is used as a medium of exchange. When a firm in the steel industry looks at the prospect of hiring new workers, the counterpart of the transaction is paying them money wages. In a Keynesian regime, the managers of the firm are unwilling to make the move because they think that it will not affect the demand they face : the newly hired workers would not buy their industry's output. In the language of the theory, a Keynesian unemployment equilibrium is efficient market by market at the quoted prices and wages when exchanges are mediated by money, if the traders believe that the actions they take on a particular market have no influence on the quantitative rations they face on the others (Benassy (1975a), Younes (1975), Grandmont, Laroque and Younes (1978)). As shown by Hart (1982) and Heller (1986), the traders' beliefs are in fact correct under plausible 
10

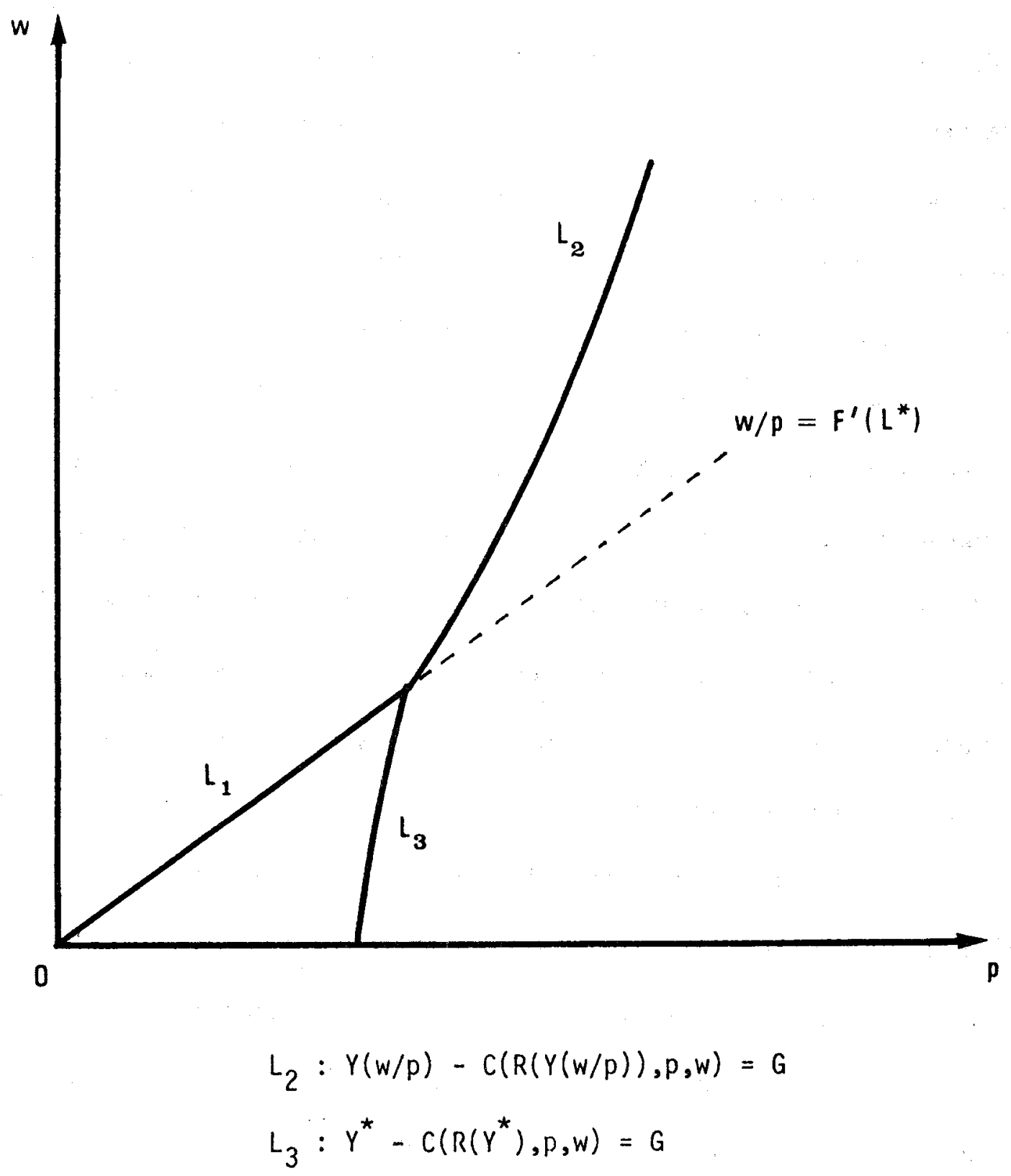

Fig - 1 
"market coordination failures", i.e. when goods and labour are exchanged for money on distinct elementary markets that are only weakly connected ${ }^{3}$. The signals then perceived rationally on each local market by the parties involved are effective demands, and these fail to inform them of the trading opportunities that are globally available (Leijonhufvud (1973), Benassy (1975b)). To make these potential gains from trade materialize at the given prices and wages, economy-wide policy interventions that increase aggregate demand are needed.

The second insight is that the short run response of the economic system to policy may depend a lot on the type of unemployment that prevails. If the quoted pair $(p, w)$ lies to the right of the curves $L_{2}$ and $L_{3}$ in Fig. 1 , policies that raise slightly aggregate demand do stimulate activity through multiplier effects, given the oredetermined price and wage. The system reacts in a Keynesian fashion, hence the name "Keynesian" unemployment given to such a regime. Aggregate demand policies have no influence on output and employment, however, if the predetermined pair $(p, w)$ lies above $L_{1}$ and to the left of $L_{2}$ in Fig. I, since economic activity is limited in that case by the supply side of the good market. Unemployment is then of the "Classical" variety and policies that raise the profitability of productive activities are required.

One gets a different but more relevant distinction between "Keynesian" and "Classical" unemployment regimes when one assumes that the output price $p$ is flexible and adjusts in the short run to clear the good market. The short run response of the system to policy shocks will then depend upon whether the nominal or the real wage is predetermined. In an unemployment regime, equilibrium output is in either case equal to $Y(W / p)$ and one ends up on the 
curve $L_{2}$ in $\mathrm{Fig.} 1$. If the predetermined variable is the nominal wage $\bar{w}$, unemployment belongs to the "Keynesian" type : a larger aggregate demand displaces the curve $L_{2}$ to the right, which yields a higher price, a lower real wage and thus a greater output. If the real wage $w / p=\bar{w}$ is predetermined, equilibrium employment and output are independent of the level of aggregate demand. Increasing public expenditures would lead in that case to an equal decrease of private demand through higher prices and wages (crowding out). Unemployment is then of the "Classical" variety and supply side policies that raise the profitability of production are called for.

These comparative statics exercices rest on the assumption that predetermined nominal or real wages (or prices) do not respond to variations of current policy parameters. After all, initial wages and prices could have moved in advance in response to anticipated systematic policy changes, or could have been quoted conditionally on current policy shocks. The foregoing policy evaluations are thus valid, strictly speaking, only in the case where systematic policy variations are unanticipated by the private sector, and where individual traders cannot, or choose not to, index prices and/or wages on policy parameters. An accurate appraisal of the consequences of policy requires a complete dynamic setup where the influences of expectations about policy on wage and price setting are consistenly taken into account. Yet the broad insights gained by looking at the above models with predetermined prices and/or wages will remain valid when considering frameworks involving endogenous price and wage setting. Unemployment will be "Keynesian" in the presence of "nominal rigidities" ; demand policies will have then multiplier effects upon the activity level. Unemployment will be "Classical" and demand shocks will tend to 
crowd out the private sector if the rigidities are "real"; in the latter case, Classical supply side policies are appropriate." The idea is hardly new : it can be found in Keynes, who spent a lot of time arguing that wages are set in nominal rather than real terms. Many modern works on the "microeconomic foundations of macroeconomics" may be viewed in part as attempts to understand why there are such nominal rigidities in the economic system.

\section{Price and wage setting}

It has long been clear that there is a close connection between the Keynesian approach to unemployment and "imperfect competition". Prices were determined in Keynesian macroeconomic models of the late 1960's through constant or variable mark-up pricing rules. Wages were determined through various versions of the so-called Phillips' curve, that were intended to reflect the outcome of underlying bargaining processes between workers and firms, and costiy adjustments. The microeconomic models with quantity rationing reviewed in the previous section were in effect imbedded explicitly in the mid$1970^{\prime} s$ in general temporary equilibrium frameworks with endogenous prices and wages, along the lines laid down by Negishi (1961) to analyze monopolistic competition (Benassy (1973, 1976), Grandmont and Laroque (1976), Negishi (1977, 1979)). The principle of the approach is clear enough. Traders are endowed with beliefs about the relation between perceived quantity rations and quoted prices (perceived demand or supply schedules) and choose the price(s) they control at the outset of each date, for instance by equating marginal cost and expected marginal revenue. The ensuing temporary equilibrium is then 
achieved by quantity rationing at the quoted prices. These theoretical investigations made clear, at a formal level, that Keynesian macroeconomic models could be viewed as temporary equilibrium models with optimizing traders operating under conditions of imperfect competition.

Introducing monopolistic or oligopolistic competitionoon the good market, in the simple model described in Section 1, leads to a short run situation - if we assume that the firms know the true (deterministic) downward sloping demand they face - where the firms' supply is indeed constrained by the level of aggregate demand. If there is for some reason unemployment on the labour market, one will end up in the interior of the region to the right of $\mathrm{L}_{2}$ and $L_{3}$ in Fig. 1. Yet analyzing the short run response of the system to policy shocks yields essentially the same conclusions as those that were obtained earlier under the assumption of perfect competition on the good market. The system will react in a Keynesian manner if there are nominal wage "rigidities", in a Classical way if the "rigidity" is real. To see this point, suppose that there are $n$ identical firms with minimum cost functions $c(Y, D, W)$, where $Y$ is individual output and $p, w$ stand for the current nominal price and wage as before. Under the usual conditions of rising marginal costs, concavity of the firms' profit functions, etc .., a symmetric monopolistic or oligopolistic equilibrium leads to the equality of marginal costs and of marginal revenues, 1.e. to a relation of the form

$$
\frac{\partial c}{\partial Y}(Y, p, w)=p\left(1-\frac{1}{n \varepsilon}\right),
$$

where $\varepsilon>1 / n$ is the elasticity of demand with respect to the current price. When there is no money fllusion, the firms' cost functions should be homogenous 
of degree 1 in $(p, w)$. Thus, if we assume away the exceptional case where marginal cost is constant, (2.1) determines generally, given $n$ and $\varepsilon$. individual output $Y$ as a function of the real wage $w / p$. Perfect competition on the good market would correspond to setting ne equal to infinity in (2.1). It should be now clear that policy evaluations will be quite similar under imperfect or perfect competition on the good market, if one makes the not implausible assumption that the number of firms and the elasticity of demand are not significantly altered by aggregate demand shocks. If one is in an unemployment regime and the nominal wage is "sticky", increasing aggregate demand will raise the current price, lower the real wage and lead to a larger output. The system reacts then in a "Keynesian" manner. In contrast, equilibrium output and employment will be determined by (2.1) when there are real wage rigidities, independently of the level of aggregate demand.

Increasing public expenditures will thus tend to crowd out the private sector. The unemployment regime is "Classical" in that case.

There are now quite a number of competing theories to explain why wages may fail to adjust and clear labour markets even in the presence of a significant rate of unemployment. Approaches that rely upon the existence of trade unions are only partially relevant, as they do not help in understanding why unemployed workers are prevented from getting hired at lower wages. On the other hand, search models appear only able to rationalize transitory or "frictional" unemployment. Many microeconomic theories that have been recently designed to account for a persistent excess labour supply exploit some "incompleteness" of the market structure. Implicit contracts models (Baily (1974), Gordon (1974), Azariadis (1975)) rely upon the assumption that workers 
have limited access to capital and insurance markets. In that case, the role of wage and employment contracts is not only to guide the allocation of labour but also to provide insurance to workers. Contracting under asymmetric information may then lead to unemployment (for surveys, see Azariadis (1981a), Hart (1983), Rosen (1985), Hart and Holmstrom (1987), Cooper (1987)). Efficiency wage models are based upon the idea that there are some attributes of labour (quality, productivity, effort) that firms can observe only imperfectly, as in Radner's general equilibrium theory with incomplete information $(1968,1972)$ or Aker lof's market for "Lemons"(1970). Firms may then choose to pay high wages to improve the quality mix of the employed labour force (Weiss (1976, 1980)), to raise their workers' morale and/or to induce their employees to choose a proper effort level (Negishi(1979), Solow(1979), Shapiro and Stiglitz(1984)) 5 . Insider-outsider models introduce the additional feature that the workers' productivities are interdependent within a firm, in the spirit of the early work on the theory of teams by Marshak and Radner (1972) : workers who are already employed (the insiders) may have then some monopoly power since they can influence the productivities or the welfare of newly hired employees by withdrawing cooperation or through harassment (for a review, see Lindbeck and Snower $(1988,1989))$. In this story the number of initially employed workers is an important determinant of current employment. There is then some serial dependence in unemployment time series (Solow (1985)), i.e. some hysteresis as in Blanchard and Summers (1986). Other approaches involve sociological interactions between workers and employers (Aker lof (1982)), or the existence of social wage or effort norms inherited from the past (Hahn (1982), Oswald (1986)). 
These (not mutually exclusive) developments are important steps toward a better understanding of the unemployment phenomenon. Yet the resulting unemployment, albeit involuntary, is "Classical" when the corresponding wage "rigidity" is real. To illustrate the point, let us go back to the case considered earlier with $n$ firms interacting through imperfect competition on the good market, and assume the simple efficiency wage hypothes is formulated by Negishi and Solow. Each firm's production function is then of the form $Y=F(e(w / p) E)$, where $E$ is the number of employees and $e$ is a worker's effort, which is assumed to be unobservable by the firm but depends (in a known way) on the current real wage. If the firm has the power to choose the wage, it will do so by setting $w$, given the output leve $1 Y$ and the price $p$, so as to minimize its production cost $F^{-1}(Y) w / e(w / p)$. If the expression $e(\omega) / \omega$ reaches a global maximum at the real wage $\omega^{*}>0$, cost minimization yields

$$
w / p=\omega^{\star}, c(Y, p, w)=p F^{-1}(Y) \omega^{\star} / e\left(\omega^{*}\right)
$$

This simple version of the efficiency wage hypothesis determines therefore the current real wage and thus, through (2.1), the current activity level, given the number of firms and the elasticity $\varepsilon$, independently of the level of aggregate demand. If there is unemployment in equilibrium, one ends up indeed in the interior of the region to the right of $\mathrm{L}_{2}$ and $\mathrm{L}_{3}$ in Fig. 1. The unemployment regime is "Classical" however : in the simple case described here, nominal shocks to aggregate demand have no real effects, increasing real public expenditures will crowd out the private sector. Note that making the effort function depend on the current rate of unemployment would not change the conclusion. For cost minimization would lead to a relation (2.2) linking the real wage to output which, together with (2.1), would determine $w / p$ and $Y$, 
given the number of firms $n$ and the elasticity $\varepsilon$. The unemployment regime would still be "Classical".

As in any Classical model, one can of course get output variations through supply side effects. The firms' market power on good markets, as measured for instance by $n \varepsilon$ in (2.1), may vary during booms and depressions through the entry and exit of firms and the extent of competition (Fudenberg and Tirole (1986), Rotemberg and Saloner (1986)). Productivity, which is a determinant of marginal cost in (2.1), may also change owing to exogenous or endogenous technological shocks or - in a more complete framework where firms have to find funds to finance their activities - to variations of the cost and availability of credit or equity financing (Greenwald and Stiglitz (1987)). If a significant part of the economic system is in such a Classical involuntary unemployment equilibrium, supply side policies that affect these parameters are indeed appropriate (Lindbeck and Snower (1987)).

As remarked earlier (footnote 4 ), one can usually generate demand multipliers in Classical models of unemployment, through supply side substitution effects. To uncover most simply such a mechanism in the present case, let us modify the above efficiency wage model by assuming that there is another good, with money price $p^{\prime}$, and that a worker's effort $e$ is not only function of the real wage $w / p$ as before but also of the ratio $p / p^{\prime}$. If the "other good" is interpreted as future consumption, the ratio $p / p^{\prime}$ stands for the expected gross real interest rate. Cost minimization leads then to a relation (2.2) which determines the real wage $w / p$, and thus with (2.1), each firm's equilibrium output, as a function of $p / p^{\prime}$. It should be now clear that demand shocks that succeed in disturbing the ratio $\mathrm{p} / \mathrm{p}^{\prime}$ (e.g. temporary 
increases of public expenditures in the dynamic version of the model) will generate substitution effects between the supply of labour measured in efficiency units and consumption of the other good (or future consumption). For instance Kahn and Mookherjee (1988) exhibited a demand multiplier of this sort in a system with two sectors based on the efficiency wage "shirking" model of Shapiro and Stiglitz. Picard (1989), and Jullien and Picard (1989) developed a dynamic version of this multiplier that acts through variations of the real rate of interest. The present discussion should make clear that such demand multipliers are Classical, despite the usual claim by authors to have produced a model with some "Keynesian features". Multipliers of this sort are in fact quite similar to those found in NC intertemporal substitution macroeconomic models.

Microeconomic models of real wage rigidities are important to understand the phenomenon of involuntary unemployment. To make the system as a whole react in a Keynesian fashion to policy shocks, however, one must at least supplement such real rigidities with nominal wage or price inertia of some sort. As noted earlier, imperfect competition on the good market - together with the assumption that firms know the true deterministic demand they face - and unemployment on the labour market, yield a short run equilibrium situation corresponding to a pair $(p, w)$ that lies in the region to the right of $L_{2}$ and $L_{3}$ in Fig. 1. If for some reason the nominal price and wage are also sluggish, a shock to aggregate demand will have short run Keynesian multiplier effects, exactly along the lines spelled out in Section 1. This is what underlies the static menu costs arguments of Aker lof and Yellen (1985), Blanchard and Kiyotaki (1987) (see also Benassy (1987)). Since prices and wages are chosen 
optimally by firms, deciding to keep them unchanged following a small shock to demand involves second order profit losses. If there are small fixed costs of changing prices and wages, firms will choose to keep them fixed : small demand shocks will generate Keynesian multipliers. The approach has been extended by a number of authors to dynamic inflationary environments where traders set prices at fixed or variable intervals, with mixed results (for a useful survey, see Blanchard (1987)). Menu costs arguments point to an externality created through price setting by interdependent traders that might be conceptually important, but they do not appear completely convincing. It is unclear why costs of changing prices should be larger than those of changing such quantities as employment. At any rate, casual empiricism suggests that menu costs are not important enough in practice to generate fluctuations comparable to those that are observed in the actual economic system.

It is fair to say that economic theorists have not yet produced a convincing explanation of the nominal "rigidities" that appear to play so central a role in the Keynesian paradigm. The approach that seems to work best empirically rests upon the assumption that nominal wages are predetermined or even kept fixed for several periods, with firms being granted the right to choose the volume of employment after the relevant information has been revealed. In some models, nominal wages are assumed to be set in a nonsynchronous way for different parts of the labour force, and/or workers are supposed to care about the relative position of their nominal wages in the wage structure, an hypothesis put forward by Keynes himself (Aker lof (1969), Fisher (1977), Phelps (1978), Taylor (1979, 1980)). Models of this sort lead in effect to dynamic versions of the short run models with predetermined prices and wages 
à la Barro-Grossman, Benassy, Malinvaud, that were briefly reviewed in Section 1. The outcome of these models, not too surprisingly, is that aggregate demand shocks do generate lasting Keynesian multiplier effects ${ }^{6}$. Despite their empirical success and the apparent realism of their assumptions, these models are not quite satisfactory from a theoretical viewpoint, however, since they assume nominal wage stickiness, while one would like to derive this property from more basic principles. As we have seen, research on this issue over the last two decades has been centered on the theory of contracts in situations with incomplete and possibly asymmetric information, but fulfilled expectations. This work yielded important insights on real rigidities, but produced Classical models of involuntary unemployment where demand multipliers, when present, operate through intertemporal or intersectoral substitution effects. It remains yet to be seen whether or not this line of research can lead to a convincing theoretical explanation of sluggish nominal wages and/or prices, and of the Keynesian multipliers that are associated with them.

\section{Expectations - Driven Business Cycles}

Another important piece of the Keynesian paradigm is that a significant part of economic fluctuations may be caused by volatile expectations (market psychology, animal spirits). Keynes described in a famous passage the disorders that may occur in financial markets when the traders enter what he called a "beauty contest" by trying to outguess each other. He and his followers have kept emphasizing that major components of actual business cycles, such as investment outlays and inventory variations, are presumably driven by erratic 
expectations about the state of demand. Early work along this line led for instance to the analysis of endogenous deterministic cycles in Keynesian macroeconomic models, through the interaction of the consumption multiplier and of various versions of the investment/inventory accelerator (see, e.g. Goodwin (1951, 1982), Hicks (1950), Kalecki (1943), Metzler (1941, 1947), Rose (1967, 1969), Samuelson (1939)).

There has been recently a renewed interest in formal theories of such expectations-driven business cycles in general equilibrium frameworks. In contrast with earlier macroeconomic formulations, the modern approach relies on an explicit modelling of the traders' optimizing behaviour, which permits in principle to analyze how expectations interact with the internal mechanisms of the economic or social system to generate autonomous fluctuations. Two elements played an important role in this recent revival. The first one was the growing awareness of the fact that the internal nonlinear dynamics of an economy may yield complex periodic orbits or even "chaotic" deterministic trajectories (Benhabib and Day (1982), Grandmont (1985)). The second was the realization that there may exist, in a wide variety of contexts, a large multiplicity of stochastic equilibria generated by random factors (sunspots) that influence the traders' expectations but leave unaltered the system's fundamentals. Multiplicity of this sort has been of course a fact of life for a long time in game theory (e.g. the folk theorem in repeated games, correlated equilibria). Recent works in economics have tended to focus attention, with only a few exceptions (see e.g. Benassy (1984), Reichlin (1987)), on the existence and multiplicity of expectations-driven business cycles in competitive markets with self-fulfilling expectations (Azariadis (1981b), Cass and Shel1 (1983), 
Azariadis and Guesnerie (1986), Farmer and Woodford (1987), Woodford (1984), Grandmont (1986)). Fluctuations occur then through the interaction of the intertemporal substitution effect and the income effect associated with movements of real interest rates or real wages. Despite the obvious limitations of such models for the analysis of unemployment, these studies confirm that economic fluctuations generated by volatile expectations are compatible indeed with individual optimization whenever there are capital market imperfections. Another outcome of these studies is the conclusion that nominal shocks to aggregate demand (e.g. the money supply) may have persistent real effects even in a competitive framework with complete information and flexible prices, provided that private economic units predict rationally that such effects do occur. It remains to see how this sort of analysis can be applied in a systematic way to models involving imperfect competition and Keynesian unemployment, where multiplier and accelerator effects would play a significant role.

I shall describe briefly here the methods used in this area, with in the framework of a simple competitive economy. Consider an over lapping generations mode1, without bequests, with a single representative individual in each generation who lives two periods, works and saves in the form of money when young and consumes when old. The supply of money $M>0$ is constant. On the other hand, one unit of output (a perishable consumption good) can be produced from one unit of labour within a period. The "fundamentals" of the system are thus constant. Under the assumption of competitive markets, the real wage is 1 at all dates, and an equilibrium state in any period can be represented by a single real number : the equilibrium output $y_{t}$, which is equal to the labour supply $\ell_{t}$ of the young trader, to the consumption $c_{t}$ of the old, and to the 
equilibrium real balance $M / p_{t}$.

It is not difficult to see that this system may exhibit quite complex periodic orbits - in fact infinitely many of them - when there is an important conflict between the intertemporal substitution effect and the income effect associated with movements of the real interest rate. Consider a deterministic intertemporal equilibrium with perfect foresight. A young trader born at date $t$ will then maximize his utility for current leisure and future consumption $v_{1}\left(l^{*}-l_{t}\right)+v_{2}\left(c_{t+1}\right)$, subject to the budget constraints $p_{t} l_{t}=m_{t}=p_{t+1} c_{t+1}$, where $m_{t}$ is his demand for money. Under the usual assumptions, an interior solution is characterized by the budget constraints and the first order condition

$$
\ell_{t} v_{1}^{\prime}\left(l^{*}-\ell_{t}\right)=c_{t+1} v_{2}^{\prime}\left(c_{t+1}\right)
$$

Since in equilibrium $l_{t}=y_{t}$ and $c_{t+1}=y_{t+1}$, an intertemporal equilibrium with perfect foresight is described by a sequence of outputs $y_{t}$ that satisfies the recurrence equation

$$
v_{1}\left(y_{t}\right)=v_{2}\left(y_{t+1}\right)
$$

where $v_{1}$ and $v_{2}$ stand for the functions of the left and right members of (3.1). Since $v_{1}$ is increasing and has an inverse, the recurrence relation (3.2) can be written equivalently $y_{t}=x\left(y_{t+1}\right)$, where $x$ is equal to the composition of $v_{1}^{-1}$ and $v_{2}$. The graph of $x$, i.e. of the relation $\ell_{t}=x\left(c c_{t+1}\right)$, describes the offer curve of the representative household, that is the locus of all optimum combinations ( $\left.\ell_{t}, c_{t+1}\right)$ when the ratio $p_{t} / p_{t+1}$ varies. Whether or not this system exhibits multiple deterministic cycles with perfect foresight depends therefore on the shape of the offer curve. 
Increasing the ratio $p_{t} / p_{t+1}$ induces as usual substitution and income effects, which lead both to an increase of the demand for future consumption but work in opposite directions for current leisure. If the substitution effect dominates everywhere, the function $x$ is increasing and cycles with a period $k \geq 2$ cannot exist. The situation represented in Fig. 2 describes, on the other hand, an extreme conflict between substitution and income effects which leads to the existence of a cycle of period 3. In that case, from a theorem by Sarkovskii, there are in fact infinitely many cycles with perfect foresight : at least one cycle of period $k$, for every positive integer $k$. The existence of a cycle of period 3 is easy to verify in this simple example. Indeed, such a cycle can be identified with a fixed point of the third iterate $x^{3}$ of the map $x$ (i.e. the composition of $x$ with itself three times) that is different from a stationary state. In the case of Fig. 2 , one has $x^{3}(y)>y$ for $y$ close to 0 , and $x^{3}\left(y^{*}\right)<y^{*}$ : the function $x^{3}$ has a fixed point between 0 and $y^{*}$.

\section{Eig. 2}

These deterministic cycles are driven by expectations that vary periodically. There are also many nonexplosive stochastic equilibria generated by self-fulfilling expectations that vary randomly when the income effect is significant. Let a young trader born at $t$ believe that the price of the good $p_{t+1}$, hence $y_{t+1}=M / p_{t+1}$, will be random in the future. If the trader is an expected utility maximizer, the first order conditions of his optimization problem yield an equilibrium relation at date $t$ that looks like (3.2)

$$
v_{1}\left(y_{t}\right)=E_{t} v_{2}\left(y_{t+1}\right)
$$

where the mathematical expectation is taken relatively to the subjective 


$$
\text { IX X }
$$


conditional probability distribution of $y_{t+1}$. Suppose now that the traders observe in every period some random signals $s_{t}$ (sunspots) in a set $S$, and assume that they believe that these signals may influence equilibrium prices and quantities, although they bear no relationship with the fundamentals of the system. If the traders condition their expectations at every date $t$ on the current and past values of $s_{t}$ and $y_{t}=M p_{t}$, i.e. on

$$
I_{t}=\left(s_{t}, y_{t}, s_{t-1}, y_{t-1}, \ldots\right) \text {, }
$$

a stochastic equilibrium with self-fulfilling expectations will be described as a sequence of random variables $\left(s_{t}, y_{t}\right)$ satisfying

$$
v_{1}\left(y_{t}\right)=E\left(v_{2}\left(y_{t+1}\right) I_{t}\right)
$$

at all dates $t=1, \ldots$. There are typically inf initely many such equilibria, and they are all generated through the stochastic difference equation

$$
v_{2}\left(y_{t+1}\right)=v_{1}\left(y_{t}\right) n_{t+1} \text {. }
$$

where the positive random variables $n_{t+1}$ are functions of the information $I_{t+1}$ and have to satisfy $E\left(n_{t+1} \mid I_{t}\right)=1$, but are otherwise arbitrary ${ }^{7}$. The case where $n_{t}=1$ at all dates with probability 1 yields a deterministic equilibrium with perfect foresight. If the variables $\eta_{t}$ are actually random, one gets a nondegenerate stochastic equilibrium.

We wish to restrict attention to nondegenerate stochastic equilibria that are bounded, i.e. such that output $y_{t}$ remains in some interval $[a, b]$ with $0<a<b$. One may also require that the process $\left(s_{t}, y_{t}\right)$ be stationary (have an invariant probability measure). It is fairly easy to verify that there is no equilibrium of this sort when the offer curve is increasing, i.e. when the 
substitution effect dominates everywhere. In contrast, there are inf initely many such equilibria when there is a significant income effect.

Consideration of (3.4) or (3.5) shows indeed that for a given stochastic equilibrium, the smallest closed interval $[a, b]$ containing $y_{t}$ at all dates with probability 1 has the property that the image of the interval by $v_{1}$ is contained in its image by $v_{2}$. Since $v_{1}$ is increasing, this means that $[a, b]$ is contained in its image by the function $x$ : the interval is invariant in the deterministic recurrence from $y_{t}$ to $y_{t+1}$ induced by $y_{t}=x\left(y_{t+1}\right)$. When the substitution effect dominates everywhere, the offer curve is increasing. The only closed invariant intervals reduce then to the monetary stationary state $\bar{y}$, to the origin $y=0$, and to $[0, \bar{y}]$ if the offer curve is continuous at the origin. In that case, the only stochastic equilibrium such that output remains in some interva] $[a, b]$ with $a>0$, is degenerate and collapses to the deterministic stationary state $y_{t}=\bar{y}$.

In contrast, when the income effect is significant enough to guarantee that $\chi^{\prime}(\bar{y})<-1$, there are infinitely many invariant intervals arbitrarily near the stationary state $\bar{y}$ (Fig. 3). For any such interval [a,b], one has $v_{2}(b)<v_{1}(a)<v_{1}(b)<v_{2}(a)$.

It is then easy to construct nondegenerate stochastic equilibria ( $s_{t}, y_{t}$ ) that stay in $S \times[a, b]$ at all times. It suffices indeed, for any $I_{t}$ such that the sequence of outputs $y_{t}, y_{t-1}, \ldots$ lies in $[a, b]$, to choose random variables $n_{t+1}$ of the form

$$
n_{t+1}=f\left(s_{t+1}, I_{t}\right)
$$

where $n_{t+1}$ belongs to the interval 


$$
J\left(y_{t}\right)=\left[v_{2}(b) / v_{1}\left(y_{t}\right), v_{2}(a) / v_{1}\left(y_{t}\right)\right]
$$

and $E\left(n_{t+1} \mid I_{t}\right)=1$ - which is a lways possible because $J\left(y_{t}\right)$ contains 1 in its interior. Since the function $v_{2}$ is decreasing near the stationary state and can thus be inverted on $[a, b]$, solving (3.5) yields then a unique $y_{t+1}$ in that interval as a function of $\left(s_{t+1}, I_{t}\right)$. The resulting process $\left(s_{t}, y_{t}\right)$ remains in $S \times[a, b]$ once it starts there. When the sunspot process lies in a compact metric space and is stationary with continuous transition probabilities, one gets a stationary process $\left(s_{t}, y_{t}\right)$ by requiring for instance that the function $f$ in $(3.6)$ be continuous. For then $\left(s_{t}, y_{t}\right)$ has also continuous transition probabilities and belongs to $S \times[a, b]$, which is compact : the existence of an invariant probability follows in that case from a standard fixed point theorem.

For any invariant interval [a,b] near the deterministic stationary state $\bar{y}$, as in Fig. 3 , the foregoing construction yields in fact inf initely many nondegenerate stochastic equilibria provided that the sunspot process is $r i c h$ enough, since the function $f$ in (3.6) can be essentially chosen arbitrarily subject to the condition $E\left(n_{t+1} \|_{t}\right)=1$. The arbitrariness of $f$ shows in particular that one can get any sort of contemporaneous co-movements between sunspots and outputs (e.g., if the sunspot $s$ is a real number, $f$ can be chosen increasing or decreasing with $s_{t+1}$ ), and a high degree of persistence (e.g. $f$ can be made to depend upon sunspots and outputs in the far distant past), even when the sunspots are i.i.d.

The above analys is has interesting implications concerning the nonneutrality of variations of the money supply. Adding public spending in the present model leads to the usual conclusion that deterministic or random fluctuations of the money stock due to changes of public expenditures do have 
real effects. The same is true of fiscal policy le.g. lump sum money transfers). A more interesting issue arises when considering monetary policy, i.e. money transfers that are proportional to the traders' money balances. It is sometimes claimed that changes of the money supply engineered through that channel are identical to "monetary reforms" (changes of monetary units), and thus are bound to have no real effect if the traders have complete information and self-fulfilling expectations. To have real consequences, such changes should be misperceived by private economic units (Lucas (1972), Barro (1981)). It is fairly easy to see with the help of the foregoing example that this claim is generally false.

The main point is that the traders may use the money stocks, or the rates of growth of the money supply, as "sunspots" that influence the ir expectations and thus real allocations. Specifically, assume in the above model that money transfers are made by the Government in each period $t$, proportionally to the old trader's money balance $m_{t}$ at the gross rate $x_{t}>0$ (this is equivalent to paying a nominal rate of interest $r_{t}=x_{t}-1$ on money). Given the initial money stock $M_{0}>0$ and the process of random variables $x_{t}$, the equilibrium money supply $M_{t}$ at date $t$ evolves then over time according to the relation $M_{t}=M_{t-1} x_{t}$. It is readily verified that the equilibrium state in each period is still described in this case by a single variable, say output $y_{t}=M_{t} / p_{t}$, and that the equilibrium relationship at date $t$ is given by (3.3). Let us suppose now that the traders know the law of evolution of the money supply and that their information at $t$ is

$$
I_{t}=\left(M_{t}, y_{t}, M_{t-1}, y_{t-1}, \cdots\right) \text {. }
$$


A stochastic equilibrium is then a sequence of random variables $\left(M_{t}, y_{t}\right)$ that satisfies the equation (3.4) at all times. We are indeed in a framework where the money stock $M_{t}$, or equivalently the rate of growth of the money supply $x_{t}$. plays the role of the "sunspot" $s_{t}$ in the preceding model. We may apply accordingly the results of our previous analysis to the instance at hand. Thus in all cases, there are infinitely many (unbounded) stochastic equilibria with self-fulfilling expectations where the variations of the money supply do affect the output level. If we insist on the other hand on the output process $y_{t}$ being bounded away from 0 , we have to distinguish two possibilities. If the substitution effect dominates, there is only one such equilibrium, and it collapses to the deterministic stationary state

$$
y_{t}=M_{t-1} x_{t} / p_{t}=\bar{y}
$$

for all $t$. Changes of the rate of growth of the money supply $x_{t}$ are then superneutral, since they imply proportionate changes of the price level, and no variation of output. If there is a strong income effect, as in Fig. 3 , there are infinitely many stochastic equilibria near the deterministic stationary state, where variations of the rate of growth of the money supply have real effects. In fact, these equilibria lead generally to arbitrary, positive or negative, correlations between money, inflation and output, and involve varying degrees of persistence, i.e. of dependence of current output on past money growth rates. These conclusions hold in particular when the growth rates $x_{t}$ are i.i.d., satisfy $E\left(x_{t}\right)=1$, and have a continuous density with support $[\alpha, \beta]$ with $0<\alpha<\beta$, as in Lucas (1972); they are also valid for more complex processes. 
In the above example, the existence of multiple expectations-driven business cycles - or more precisely, the fact that such fluctuations are not arbitraged away although they are correctly foreseen - is due to the presence of capital markets imperfections : in the overlapping generations model without bequests, assets holdings are constrained to be 0 at the end of each individual's life. It is not difficult to verify that we would get exactly the same results, at least near the deterministic stationary state as for instance in Fig. 3, if we assume that members of each generation care about the utilities of their descendants, with some discounting, but that borrowing against the income of one's heirs is prohibited (or that children may reject negative bequests from the ir parents). For in that case the borrowing constraint would bite at the deterministic stationary state $\bar{y}$ and thus by continuity, in its vicinity: deterministic or stochastic equilibria with selffulfilling expectations would then satisfy equations (3.2) or (3.4) near $\bar{y}$, and the previous analysis would apply. The latter version of the model can in fact be reinterpreted as describing an economy where traders are infinitely long-lived and face in each period a cash-in-advance constraint stating that borrowing against future labour income is not feasible. In the over lapping generations interpretation, the length of the "period" is about 30-40 years ; in the cash-in-advance interpretation, periods may be viewed as quite short, say about one month (Woodford (1986)). Recent works have demonstrated moreover that an extreme conflict between substitution and income effects is by no means necessary to get nonexplosive expectations-driven business cycles : they do occur with an increasing offer curve either by introducing public expenditures into the model (Farmer and Woodford (1987), Woodford (1984), Grandmont (1986)) 
or by considering productive investment (Benhabib and Laroque (1988), Farmer (1986), Reichlin (1986), Woodford (1984, 1986)).

These studies confirm therefore, under increasingly plausible assumptions, that the old Keynesian view according to which a significant part of actual business cycles may be caused by volatile anticipations is compatible with individual optimization, flexible prices and self-fulfilling expectations whenever there are capital market imperfections - which should be the case of any model of the economy where money has a meaningful role to play. They show also that nominal shocks to aggregate demand may lead under these circumstances to output and employment fluctuations that exhibit the sort of frequencies and persistence that are observed in the actual economic system, even under complete information. The mechanisms generating these fluctuations in competitive models are not very satisfactory from a Keynesian viewpoint nor quite plausible, since they involve intertemporal substitution between leisure and consumption through movements of the real interest rate. It remains to see how the methods outlined above can be made to bear upon models with imperfect competition and Keynesian unemployment, with significant multiplier and accelerator effects.

These results confirm also in a sense another important tenet of Keynesian thinking, namely that the future is essentially unpredictable in a decentralized market economy, because from the point of view of an individual trader, a lot depends upon the (unknown) expectations of the others. The axiom of self-fulfilling expectations is very demanding in any case, since it requires that the traders know beforehand the true aggregate structure of the system, which is implausible in an economy with numerous traders with diverse 
characteristics. The issue becomes all the more acute in the cases presented above, where there exist multiple nonexplosive stochastic or deterministic equilibria: even if the traders knew the fundamentals of the system, they would be unable to make correct forecasts without knowing how the others envision the future. All this shows that in order to describe in a realistic way the evolution of any economic or social system, one should portray the traders as learning progressively the dynamic laws of their environment. Then it would be in the long run only that the self-fulfilling expectations property could be a possible outcome of the corresponding dynamics with learning. In the example presented here, the question is accordingly the evaluation of the stability of particular deterministic or stochastic equilibria with selffulfilling expectations in the dynamics associated with plausible, prespecified learning processes. That sort of issue has a long history in economics, in particular in temporary equilibrium theory (see e.g. Fuchs and Laroque (1976), Fuchs (1979)). There has been recently a renewed interest in the topic. The results are only tentative at this stage; they do suggest however, in the particular case of the simple overlapping generations model discussed above, that the deterministic stationary state $\bar{y}$ is asymptotically stable in plausible dynamics with learning when the substitution effect dominates, but is unstable when there is a strong income effect as in Fig. 3 (Grandmont (1985), Grandmont and Laroque (1986)). It is too early to have a general picture of which sort of equilibria are likely to be stable and which are not, and further research work should be devoted to this important area. But the available theoretical evidence seems already to indicate that steady states that are determined by the fundamentals of the system only are symptotically stable in 
plausible dynamics with learning when there are no sunspot equilibria nearby, whereas such "bubble-free" steady states are unstable otherwise."

\section{Concluding Remarks}

A lot of research work has been done over the last two decades on the microeconomic foundations of Keynesian macroeconomic models. These theoretical investigations have produced major qualitative insights into the workings of a decentralized capitalist economy, in particular into the mechanisms that may generate the stubborn disequilibria that we observe periodically or the somewhat erratic paths followed by quite a few economic time series.

One important outcome of this research effort has been the distinction "Classical" and "Keynesian" unemployment regimes. The basis for this distinction is not so much the presence or absence of short run policy multipliers, but rather the mechanisms through which such multipliers operate. In a "Classical" unemployment regime, multipliers work the ir way through supply side effects, e.g. through variations of the number of firms, of the extent of competition, of productivity, of the availability and the cost of credit and equity financing, or through intertemporal or intersectoral substitution effects. In contrast, "Keynesian" demand multipliers do not rely upon such supply side effects. I have argued here that in models with endogenous price and wage setting, "Classical" unemployment is associated with real "rigidities", whereas additional nominal "rigidities" appear to be necessary to generate truly "Keynesian" multipliers.

The connection between the fact that firms are constrained by the low level of demand in Keynesian macroeconomic models, and endogenous price setting in imperfectly competitive environments, was in effect formally established at 
an early stage of this research effort. More recent studies have uncovered important classes of mechanisms that can generate a persistent excess supply on labour markets : implicit contracts, efficiency wages, insiders-outsiders, sociological norms, etc .. These findings are important steps toward a better understanding of the multi-faceted unemployment phenomenon, and much more work is needed along these avenues. Yet the wage "rigidities" that come out of these models are real. This feature, together with the assumption of imperfect competition on the goods markets, leads accordingly to unemployment regimes that are "Classical". Research on these issues over the last two decades focussed on the theory of incomplete contracts with possibly asymmetric information and fulfilled expectations. It remains to be seen whether this approach, which yielded important insights on real rigidites, can also generate a good theoretical explanation of sluggish nominal wages and/or prices.

Another important outcome of the research effort has been the confirmation of a central piece of the Keynesian story, i.e. of the fact that a capitalist economy may undergo highly erratic fluctuations that are due to volatile expectations. Recent findings have shown in particular that an amazing multiplicity of stochastic ("sunspot") equilibria can arise in competitive dynamic frameworks with optimizing individuals and self-fulfilling expectations, whenever there are capital market imperfections. As a simple corollary of these results, one gets that monetary policy (proportional money transfers) may have persistent real effects even under complete information, if economic units take the money growth rates as "sunspots" that can affect real allocations. Much more work is needed in this important area, in particular on the formal characterization of the general configurations leading to the 
existence of multiple stochastic sunspot equilibria. Ultimately, one would like to apply these methods in a systematic way to policy evaluation in dynamic models with real and nominal "rigidities" and Keynesian unemployment.

The bottom line may turn out to be, in the end, that the axioms used in many of the recent works on the "microeconomic foundations of macroeconomics" to describe the behaviour of economic units in uncertain environments (expected utility maximization, fulfilled expectations), are empirically wrong. People may be "rational", but they simply lack the information to form correct expectations under conditions of rapid change. As noted in the text, this issue is all the more acute when the economic system has a large multiplicity of deterministic or stochastic equilibria. In such a context, studying the stability of deterministic or stochastic equilibria with fulfilled expectations in the dynamics associated with plausible and general learning processes, in an important topic for future research. More realistic assumptions about the actual behaviour of economic units in uncertain environments may in fact provide the sort of framework needed to explain Keynesian nominal "rigidities" and their corresponding demand multipliers. Such nominal inertia might be, for instance, the consequence of significant departures from the expected utility hypothesis, or of nominal short run "rigidities" in the adjustment of expectations to a rapidly changing or unknown environment. Keynes, and after him the post-Keynesians, have emphasized repeatedly that we may live in a world where the future is essentially unpredictable, even in terms of subjective probabilities, i.e. where there is Knightian uncertainty. The reason why orthodox economic theorists have not followed up this lead, is presumably that we do not have yet formal models of decision making in such environments that 
would yield operational behavioural predictions (for an interesting attempt in that direction, see Bewley $(1986,1987))$. Progress on these questions might turn out to be the key to a proper understanding of real and nominal "rigidities", and thus of the disequilibrium processes at work in market economies. 
* Paper prepared for the 90th Anniversary Symposium of the Scandinavian Journal of Economics, "Whither Macroeconomics", Helsinki, June 12-14, 1988. The financial supports of the Institute for International Economic Studies and the Department of Economics, Stockholm University, during the spring of 1988, are gratefully acknowledged.

* CNRS and CEPREMAP 142, rue du Chevaleret, 75013 PARIS. I am thankful to Jean-Pascal Benassy for numerous enlightening discussions, and to Seppo Honkapohja for his perceptive comments on an earlier draft.

1. Elements of these examples can be found in Solow and Stiglitz (1968), Younès (1970). The structure of equilibria with quantity rationing at predetermined prices was made precise in a general microeconomic framework by Benassy (1975a), Drèze (1975), Younès (1975).

2. There are two other possible regimes associated with an excess demand of labour : "Repressed Inflation" where there is an excess demand of the good, and "Underconsumption" where there is an excess supply of output. Repressed Inflation corresponds to the region between $L_{1}$ and $L_{3}$ in $F i g . ~ I$; the Underconsumption region reduces to the curve $L_{3}$ in the simple example considered here.

3. For instance, Hart postulates the existence of a large number of spatially distinct markets for the good and similarly, for labour. A large number of identical firms and households are distributed uniformly over these markets. Hart assumes essentially that (1) if a firm and a household face each other on an elementary labour market, then they do not participate in the same good market and (2) there are no spillovers between elementary good markéts, nor between labour markets. The main implication of this "market coordination failure" is that the managers of a particular firm can predict correctly that what they do on their labour market will not affect the households' demand curve for their output. Similarly, members of a particular household know that their actions on their good market will have no influence on the demand curve for labour that they face in the specific labour market to which they are allocated. There is now a growing literature on Keynesian "market coordination failures", see Cooper and John (1988), Rotemberg (1987). 
4. The analysis of the consequences of demand shocks in situations of Keynesian and Classical unemployment is in fact a little more subtle than this short discussion suggests. Classical models of unemployment with "real rigidities" can give rise to demand multipliers, with an intensity that may be greater than 1, but such multipliers rely upon significant intertemporal or intersectoral (in a setup with several production sectors) supply side substitution effects. In contrast, models of Keynesian unemployment with "nominal rigidities" generate demand multipliers that do not rely on supply side effects. A well known example of a Classical multiplier, in a competitive framework with no unemployment, was provided by Lucas (1972). More recent examples of demand multipliers that are in fact Classical, in models "with "real rigidities" and unemployment, can be found in Hart (1982), Kahn and Mookherjee (1988), Picard (1989), Jullien and Picard (1989). We shall come back to this point in the next section.

5. For useful surveys, see Akerlof and Yellen (1986), Weiss (1989). 6. One limitation of macroeconomic models of this type is that there are only able to handle Keynesian unemployment as output is demand-determined. For an interesting study of the consequences of demand shocks in a dynamic microeconomic model with monopolistic competition, predetermined prices and self-fulfilling expectations, see L.E.O. Svensson (1986).

7. The only thing one has to take care of is that the output sequences generated through $(3.5)$ remain feasible.

8. For studies of stochastic equilibria with proportional money transfers and their relations with sunspot equilibria, see Farmer and Woodford (1987), Chiappori and Guesnerie (1988).

9. The stability of sunspot equilibria under specific learning dynamics has been investigated by Evans (1987), Woodford (1987), Evans and Honkapohja (1988). 


\section{REFERENCES}

Akerlof, G. : Relative wages and the rate of inflation, Quarterly Journal of Economics 83, 353-374, 1969.

Akerlof, G. : The market for "lemons" : Quality uncertainty and the market mechanism, Quarterly Journal of Economics 84, 488-500, 1970.

Akerlof, G. : Labor contracts as partial gift exchange, Quarterly Journal of Economics 97, 543-569, 1982. Reprinted in Aker lof, G. and Yellen, J. (eds.), 1986.

Akerlof, G. and Yellen, J. : A near rational model of the business cycle with wage and price inertia, Quarterly Journal of Economics 100, 823-838, 1985.

Akerlof, G. and Yellen, J. (eds.) : Efficiency Wage Models of the Labor Market, Cambridge University Press, Cambridge and New York, 1986.

Azariadis, C. : Implicit contracts and underemployment equilibria, Journal of Political Economy 83, 1183-1202, 1975.

Azariadis, C. : Implicit contracts and related topics : A survey, in Horste in, Z., et al. (eds.), The Economics of the Labour Market, HMSO, London, 1981 a.

Azariadis, C. : Self-fulfilling prophecies, Journal of Economic Theory 25, 380$396,1981 b$.

Azariadis, C. and Guesnerie, R. : Sunspots and cycles, Review of Economic Studies 53, 725-737, 1986.

Baily, M.N. : Wages and employment under uncertain demand, Review of Economic Studies 41, 37-50, 1974.

Barro, R.J. : Money, Expectations and Business Cycles, Academic Press, New York, 1981 .

Barro, R.J. and Grossman, H.I. : A general disequilibrium model of income and employment, American Economic Review 61, 82-93, 1971.

Barro, R.J. and Grossman, H.I. : Suppressed inflation and the supply multiplier, Review of Economic Studies 41, 87-104, 1974.

Barro, R.J. and Grossman, H.I. : Money. Employment and Inflation, Cambridge University Press, Cambridge and New York, 1976.

Benassy, J.P. : Disequilibrium Theory, Ph.D. Dissertation, University of California, Berkeley, 1973.

Benassy, J.P. : Neo-Keynesian disequilibrium theory in a monetary economy, Review of Economic Studies 42, 503-523, 1975a. Reprinted in Grandmont, J.M. (ed. ), 1988. 
Benassy, J.P. : Disequilibrium exchange in barter and monetary economies, Economic Inquiry 13, 131-156, 1975b.

Benassy, J.P. : The disequilibrium approach to monopolistic price setting and general monopolistic equilibrium, Review of Economic Studies 43, 69-81, 1976.

Benassy, J.P. : A neo-Keynesian model of price and quantity determination in disequilibrium, in Schwödiauer, G. (ed.), Equilibrium and Disequilibrium in Economic Theory, D. Reidel Pub. Co., Boston, 1977.

Benassy, J.P. : A non-Walrasian model of the business cycle, Journal of Economic Behavior and Organization 5, 77-89, 1984.

Benassy, J.P. : Imperfect competition, unemployment and policy, European Economic Review 31, 417-426, 1987.

Benhabib, J. and Day, R.H. : A characterization of erratic dynamics in the over lapping generations mode 1, Journal of Economic Dynamics and Control 4, 37-55, 1982.

Benhabib, 3. and Laroque, G. : On competitive cycles in productive economies, Journal of Economic Theory 45, 145-170, 1988.

Bewley, T. : Knightian decision theory : Part I, Cowles Foundation DP 807 , Yale University, 1986.

Bewley, T. : Knightian decision theory, Part 11 : Intertemporal problems, Cowles Foundation DP 835, Yale University, 1987.

Blanchard, 0. : Why does money affect output ? A survey, NBER WP 2285, 1987.

Blanchard, 0 . and Kiyotaki, N. : Monopolistic competition and the effects of aggregate demand, American Economic Review 77, 647-666, 1987.

Blanchard, O. and Summers, L.H. : Hysteresis and the European unemployment problem, NBER Macroeconomics Annual I, MIT Press, Cambridge, 15-77, 1986.

Cass, D. and She11, K. : Do sunspots matter ? Journal of Political Economy 91, 193$227,1983$.

Chiappori, P.A. and Guesnerie, R. : Self-fulfilling prophecies : The sunspot connection, EHESS Working Paper, Paris, 1988.

Clower, R.W. : The Keynesian counterrevolution : A theoretical appraisal, in Hahn, F.H. and Brechling, F.P.R. (eds.), The Theory of Interest Rates, McMillan, London, 1965.

Cooper, R.W. : Wage and employment patterns in labor contracts : Microfoundations and Macroeconomic implications, Fundamentals of Pure and Applied Economics, Harwood Academic Publishers, London and New York, 1987. 
Cooper, R.W. and John, A. : Coordinating coordination failures in Keynesian mode 1s, Quarterly Journal of Economics 103, 441-463, 1988.

Dreze, J. : Existence of an exchange equilibrium under price rigidities, International Economic Review 16, 301-320, 1975.

Evans, G. : The fragility of sunspots and bubbles, IMSSS TR 514, Stanford University, 1987.

Evans, G. and Honkapohja, S. : On the robustness of bubbles in linear rational expectations models, mimeo, London School of Economics and Turku School of Economics, 1988.

Farmer, R.E.A. : Deficits and cycles, Journal of Economic Theory 40, 77-88, 1986.

Farmer, R.E.A. and Woodford, M. : Self-fulfilling prophecies and the business cycle, Cuadernos Economicos de ICE, 1987.

Fisher, S. : Long term contracts, rational expectations and the optimal money supply rule, Journal of Political Economy 85, 163-190, 1977.

Fuchs, G. : Is error learning behavior stabilizing? Journal of Economic Theory 20. 300-317, 1979. Reprinted in Grandmont, J.M. (ed.), 1988.

Fuchs, G. and Laroque, G. : Dynamics of temporary equilibria and expectations, Econometrica 44, 1157-1178, 1976. Reprinted in Grandmont, J.M. (ed.), 1988.

Fudenberg, D. and Tirole, J. : Dynamic models of oligopoly, Eundamentals of Pure and Applied Economics, Harwood Academic Publishers, London and New York, 1986.

Goodwin, R.M. : The non-linear accelerator and the persistence of business cycles, Econometrica 19, 1-17, 1951.

Goodwin, R.M. : Essays in Economic Dynamics, McMillan, London and New York, 1982.

Gordon, D.F. : A neo-Classical theory of Keynesian unemployment, Economic Inquiry 12, 431-459, 1974 .

Grandmont, J.M. : On endogenous compet itive business cycles, Econometrica 53, 995$1045,1985$.

Grandmont, J.M. : Stabilizing competitive business cycles, Journal of Economic Theory 40, 57-76, 1986.

Grandmont, J.M. (ed.), Temporary Equilibrium. Selected Readings, Academic Press, New York, 1988.

Grandmont, J.M. and Laroque, G. : On temporary Keynesian equilibria, Review of Economic Studies 43, 53-67, 1976.

Grandmont, J.M. and Laroque, G. : Stability of cycles and expectations, Journal of Economic Theory 40, 138-151, 1986. 
Grandmont, J.M., Laroque, G. and Younes, Y. : Equilibrium with quant ity rationing and recontracting, Journal of Economic Theory 19, 84-102, 1978. Reprinted in Grandmont, J.M. (ed.), 1988.

Greenwald, N. and Stiglitz, J.E. : Keynesian, New Keynesian and New Classical economics, Oxford Economic Papers 39, 119-132, 1987.

Hahn, F.H. : Money and Inflation, Basil Blackwe11, Oxford, 1982.

Hansen, B. : A Study in the Theory of Inflation, Allen and Unwin, London, 1951. Hart, 0. : A model of imperfect competition with Keynesian features, Quarterly Journal of Economics 97, 109-138, 1982. Reprinted in Grandmont, J.M. (ed.), 1988.

Hart, 0. : Optimal labour contracts under asymmetric information : An introduction, Review of Economic Studies 50, 3-35, 1983.

Hart, 0. and Holmstrom, B. : The theory of contracts, in Bewley, T. (ed.), Advances in Economic Theory. Fifth World Congress, Econometric Society Monographs, Cambridge University Press, Cambridge and New York, 1987.

Heller, W.P. : Coordination failure under complete markets with applications to effective demand, in Heller, W.P., Starr, R.M., and Starrett, D.A. (eds.), Essays in Honor of Kenneth J. Arrow, Vol. II. Equilibrium Analysis, Cambridge University Press, Cambridge and New York, 1986.

Hicks, J. : A Contribution to the Theory of the Trade Cycle, The Clarendon Press, Oxford, 1950.

Jullien, B. and Picard, P. : Efficiency wage and macroeconomic policy: A dynamic model with rational expectations, mimeo, CEPREMAP, Paris, 1989.

Kahn, C. and Mookherjee, D. : A competitive efficiency wage model with Keynesian features, Quarterly Journal of Economics 103, 609-645, 1988.

Kalecki, M. : Studies in Economic Dynamics, Allen and Unwin, London, 1943.

Leijonhufvud, A. : On Keynesian Economics and the Economics of Keynes, Oxford University Press, Oxford, 1968.

Leijonhufvud, A. : Effective demand failures, Swedish Journal of Economics 75, 27$58,1973$.

Lindbeck, A. and Snower, D. : Transmission mechanisms from product to the labor market, Institute for International Economic Studies, Seminar Paper 403, University of Stockholm, 1987.

Lindbeck, A. and Snower, D. : Cooperation, harassment, and involuntary unemployment : An insider-outsider approach, American Economic Review 78, 167$188,1988$. 
Lindbeck, A. and Snower, D. : The Insider-Outsider Theory of Employment and Unemployment, MIT Press, Cambridge, 1989.

Lucas, R.E., Jr. : Expectations and the neutrality of money, Journal of Economic Theory 4, 103-124, 1972. Reprinted in Lucas, R.E., Jr., 1981.

Lucas, R.E., Jr. : An equilibrium model of the bus iness cycle, Journal of Political Economy 83, 1113-1144, 1975. Reprinted in Lucas, R.E., Jr., 1981.

Lucas, R.E., Jr. : Studies in Business Cycle Theory, MIT Press, Cambridge, 1981. Lucas, R.E., Jr. and Sargent, T.J. : After Keynesian macroeconomics, Federal Reserve Bank of Minneapolis Quarterly Review 3, 1979. Reprinted in Lucas, R.E., Jr. and Sargent, T.J. (eds.), Rational Expectations and Econometric Practice, Vol. I, The University of Minnesota Press, Minneapolis, 1981.

Malinvaud, E. : The Theory of Unemployment Reconsidered, Basil Blackwe11, Oxford, 1977.

Marshak, J. and Radner, R. : Economic Theory of Teams, Yale University Press, New Haven, 1972.

Metzler, L.A. : The nature and stability of inventory cycles, Review of Economics and Statistics 23, 113-129, 1941.

Metzler, L.A. : Factors governing the length of inventory cycles, Review of Economics and Statistics 29, 1-15, 1947.

Negishi, T. : Monopolistic competition and general equilibrium, Review of Economic Studies 28, 196-201, 1961.

Negishi, T. : Existence of an underemployment equilibrium, in Schwödiauer, $G$. (ed.), Equilibrium and Disequilibrium in Economic Theory, D. Reidel Pub. Co., Boston, 1977.

Negishi, T. : Microeconomic Foundations of Keynesian Macroeconomics, North Holl land, Amsterdam, 1979.

Oswald, A.J. : Is wage rigidity caused by "lay-offs by seriority" ? in Beckerman, W. (ed.), Wage Rigidity and Unemployment, Duckworth and Co., London, 1986.

Patinkin, D. : Money. Interest and Prices, Harper and Row, New York, 1956. 2nd edition, 1965.

Phelps, E. : Disinflation without recession : Adaptative guideposts and monetary policy, Weltwitschaftitches Archiv 100, 1978. Reprinted in Phelps, E. (ed.), Employment and Inflation, Vol. I, Academic Press, New York, 1979.

Picard, P. : Chômage involontaire et salaire d'efficience, mimeo, CEPREMAP, Paris, 1989. 
Radner, R. : Competitive equilibrium under uncertainty, Econometrica 36, 31-58, 1968.

Radner, R. : Existence of equilibrium of plans, prices, and price expectations in a sequence of markets, Econometrica 40, 289-304, 1972.

Reichlin, P. : Equilibrium cycles in an overlapping generations economy with production, Journal of Economic Theory 40,89-102, 1986.

Reichlin, P. : Output-inflation cycles in an economy with staggered wage setting, mimeo, University of Roma, 1987.

Rose, H. : On the non-linear theory of the employment cycle, Review of Economic Studies $34,153-173,1967$.

Rose, H. : Real and monetary factors in the business cycle, Journal of Money. Credit, and Banking 1, 138-152, 1969.

Rosen, S. : Implicit contracts, a survey, Journal of Economic Literature 23, 1144$1175,1985$.

Rotemberg, J. : The New Keynesian microfoundations, mimeo, MIT, 1987.

Rotemberg, J. and Saloner, G. : A supergame theoretic model of price wars during booms, American Economic Review 76, 390-407, 1986.

Samuelson, P.A. : Interaction between the multiplier analys is and the principle of acceleration, Review of Economics and Statistics 21, 75-78, 1939.

Shapiro, C. and Stiglitz, J.E. : Equilibrium unemployment as a worker discipline device, American Economic Review 74, 433-444, 1984. Reprinted in Aker lof, G. and Yellen, J. (eds.), 1986.

Solow, R.M. : Another possible source of wage stickiness, Journal of Macroeconomics 1, 79-82, 1979. Reprinted in Akerlof, G. and Yellen, J. (eds.), 1986.

Solow, R.M. : Insiders and outsiders in wage determination, Scandinavian Journal of Economics 87, 711-728, 1985.

Solow, R.M. and Stiglitz, J.E. : Output, employment and wages in the short run, Quarterly Journal of Economics 82, 537-560, 1968.

Svensson, L.E.O. : Sticky goods prices, flexible asset prices, monopolistic competition, and monetary policy, Review of Economic Studies 53, 385-405, 1986.

Taylor, J. : Staggered price setting in a macro model, American Economic Review 69 , $108-113,1979$.

Taylor, J. : Aggregate dynamics and staggered contracts, Journal of Political Economy 88, 1-24, 1980. 
Weiss, A.M. : A Theory of Limited Labor Markets, Ph.D. Dissertation, Stanford University, 1976.

Weiss, A.M. : Job queues and layoffs in labor markets with flexible wages, Journal of Political Economy 88, 526-538, 1980. Reprinted in Aker lof, G. and Yellen, J. (eds.), 1986.

Weiss, A.M. : Efficiency wage mode is of unemployment, Eundamentals of Pure and Apolied Economics, Harwood Academic Publishers, London and New York, 1989.

Woodford, M. : Indeterminacy of equilibrium in the over lapping generations mode 1 : A survey, mimeo, University of Chicago, 1984.

Woodford, M. : Stationary sunspot equilibria in a finance constrained economy, Journal of Economic Theory 40, 128-137, 1986.

Woddford, M. : Learning to believe in sunspots, mimeo, University of Chicago, 1987.

Younes, $Y$. : Sur les notions d’équilibre et de déséquilibre utilisées dans les modè les décrivant l'évolution d'une économie capitaliste, mimeo, CEPREMAP, Paris, 1970.

Younes, $Y$. : On the role of money in the process of exchange and the existence of a non-Walrasian equilibrium, Review of Economic Studies 42, 489-501, 1975. 